\title{
Seroprevalence of transfusion transmitted infections in voluntary and replacement donors: A five years study
}

\author{
Ashish Tayde', Chetna Agrawal ${ }^{2, *}$, A. T. Deshmukh ${ }^{3}$ \\ ${ }^{\mathbf{1}}$ Associate Professor, ${ }^{\mathbf{A}}$ Assistant Professor, ${ }^{3}$ Professor and HOD, Dept. of Pathology, Dr. Panjabrao Deshmukh Memorial Medical \\ College, Amravati, Maharashtra, India \\ *Corresponding Author: \\ Email: drchetnaagrawal@gmail.com
}

\begin{abstract}
The transfusion of blood and its component is very essential health care modality wherein it saves life, but can also be hazardous to recipients. Despite of stringent screening methods done prior to transfusion there is always a bleak possibility of getting infections like HIV, HCV, HBV, Treponema pallidum and malaria. This study was a retrospective study carried out at Blood Bank and Component Lab, Dr. Panjabrao Deshmukh Memorial Medical College, Amravati over period of five years. A total of 52606 donor's blood was collected over the period of 5 years (From $1^{\text {st }}$ January 2012 to $31^{\text {st }}$ December 2016). Out of these $45,796(87.05 \%)$ were voluntary blood donations and 6,810 (12.94\%) were replacement Blood donations. The overall seropositivity for all TTIs (HIV, HCV, HBV, Treponema pallidum and malaria) over a period of five years was found to be 1425 $(2.71 \%)$ in which $1081(2.36 \%)$ were voluntary donors and $344(5.05 \%)$ were replacement donors. It was observed from the findings of this study that seropositivity rate of TTIs was less among voluntary donors. It was concluded that to improve blood safety extensive donor selection, use of sensitive screening and establishing strict guidelines in blood transfusion will help us to reduce burden of TTIs in our society.
\end{abstract}

Keywords: Seroprevalence, Seropositivity, TTIs, Voluntary donors, Replacement donors.

\section{Introduction}

Blood transfusion services is a vital part of modern health care with the aim to provide safe and effective blood and blood products to the needy. ${ }^{1}$ The transfusion of blood and its component is very essential health care modality wherein it saves life, but can also be hazardous to recipients. There is always a risk (1\%) associated with transfusion including Transfusion Transmitted Infections (TTIs). ${ }^{2}$ Despite of stringent screening methods done prior to transfusion there is always a bleak possibility of getting infections like HIV, HCV, HBV, Treponema pallidum and malaria. ${ }^{3}$ To prevent the transmission of infections through transfusion and to make it effective various factors are involved that includes sensitivity, specificity of test, window period of infection, variant of viruses, cost and method of test and staff carrying out the test. Blood collected from low risk population has low percentage of TTIs, ${ }^{4}$ hence voluntary donor has less prevalence of TTIs when compared with replacement and paid donor. ${ }^{5}$ The key to reduce the risk involved in blood transfusion related infections is to educate, motivate and to promote voluntary blood donation. ${ }^{6}$ This study was conducted with aim to find the prevalence of various TTIs in our blood bank and compare prevalence rate in voluntary and replacement donors.

\section{Materials and Methods}

This study is a retrospective study carried out at Blood Bank and Component Lab, Dr. Panjabrao Deshmukh Memorial Medical College, Amravati. The duration of study was 5 years ( $1^{\text {st }}$ January 2012 to 31
December 2016). All the donors (Voluntary and replacement) who fulfill the criteria laid down by National Blood Transfusion council were included in this study. During collection of Blood, Blood samples were collected for TTI testing in Pilot test tube. All the test were performed under strict supervision of Blood Transfusion officer. All ELISA testings (HIV, HBsAg, HCV) were done on DS2 Fully Automated ELISA processor. HIV tests were done using HIV Advance, $4^{\text {th }}$ Generation kit, BeneSphera, Avantor Performance Materials India Ltd. For testing Hepatitis B virus, HBsAg ELISA was done using BeneSphera $3^{\text {rd }}$ generation ELISA kit, Avantor Performance Materials India Ltd. HCV testing was done using BeneSphera, $3^{\text {rd }}$ generation ELISA kit, Avantor Performance Materials India Ltd. Test for Syphilis was done by using Aspen Syphilis Rapid test strip, Aspen Labs Pvt. Ltd. Lastly Malaria tests were done using Rapid Malaria Antigen Card test, Malerigen (P.f/Pan Antigen), Aspen Labs Pvt. Ltd. All tests were performed according to instructions provided by kit manufacturer and was done by trained and approved staff under supervision of Blood Transfusion officer.

\section{Results}

A total of 52606 donor's blood was collected over the period of 5 years (From $1^{\text {st }}$ January 2012 to $31^{\text {st }}$ December 2016). Out of these $45,796(87.05 \%)$ were voluntary blood donations and 6,810 (12.94\%) were replacement Blood donations (Table 1). 
Table 1: Distribution of donors

\begin{tabular}{|l|c|c|c|}
\hline \multirow{2}{*}{ Year } & \multicolumn{3}{|c|}{ Total Collection } \\
\cline { 2 - 4 } & Voluntary Donations & Replacement Donations & Total \\
\hline 2012 & $8477(80.82 \%)$ & $2012(19.18 \%)$ & 10489 \\
\hline 2013 & $8950(84.95 \%)$ & $1585(15.04 \%)$ & 10535 \\
\hline 2014 & $9658(87.38 \%)$ & $1395(12.62 \%)$ & 11053 \\
\hline 2015 & $8422(88.40 \%)$ & $1105(11.60 \%)$ & 9527 \\
\hline 2016 & $10289(93.52 \%)$ & $713(6.48 \%)$ & 11002 \\
\hline Total & $45796(87.05 \%)$ & $6810(12.94 \%)$ & 52606 \\
\hline
\end{tabular}

Screening for HIV was done on all 52606 donors samples which showed total positivity for HIV in $216(0.41 \%)$ cases. Out of these 216 HIV positive donors, 137 (0.30\%) were voluntary donors and 79 (1.16\%) were replacement donors (Table 2).

Table 2: HIV seropositive cases in donors

\begin{tabular}{|l|c|c|c|c|c|c|}
\hline Year & \multirow{2}{*}{$\begin{array}{c}\text { Total } \\
\text { Donors }\end{array}$} & $\begin{array}{c}\text { Total HIV } \\
\text { positive } \\
\end{array}$ & & \multicolumn{2}{|c|}{ Voluntary Donors } & \multicolumn{2}{c|}{ Replacement Donors } \\
\cline { 4 - 7 } & & Tonors & Total & HIV Positive & Total & HIV Positive \\
\hline 2012 & 10489 & $76(0.72 \%)$ & $8477(80.82 \%)$ & $34(0.40 \%)$ & $2012(19.18 \%)$ & $42(2.10 \%)$ \\
\hline 2013 & 10535 & $77(0.73 \%)$ & $8950(84.95 \%)$ & $44(0.49 \%)$ & $1585(15.04 \%)$ & $33(2.08 \%)$ \\
\hline 2014 & 11053 & $23(0.21 \%)$ & $9658(87.38 \%)$ & $21(0.22 \%)$ & $1395(12.62 \%)$ & $02(0.14 \%)$ \\
\hline 2015 & 9527 & $25(0.26 \%)$ & $8422(88.40 \%)$ & $23(0.27 \%)$ & $1105(11.60 \%)$ & $02(0.18 \%)$ \\
\hline 2016 & 11002 & $15(0.15 \%)$ & $10289(93.52 \%)$ & $15(0.15 \%)$ & $713(6.48 \%)$ & 00 \\
\hline Total & 52606 & $216(0.41 \%)$ & $45796(87.05 \%)$ & $137(0.30 \%)$ & $6810(12.94 \%)$ & $79(1.16 \%)$ \\
\hline
\end{tabular}

Seropositivity for HBV was found in total $740(1.41 \%)$ donors, out of which $571(1.25 \%)$ were voluntary donors and $169(2.48 \%)$ were replacement donors (Table 3$)$.

Table 3: HBV seropositive cases in donors

\begin{tabular}{|l|c|c|c|c|c|c|}
\hline Year & \multirow{2}{*}{$\begin{array}{c}\text { Total } \\
\text { Donors }\end{array}$} & $\begin{array}{c}\text { Total HBV } \\
\text { positive } \\
\end{array}$ & & \multicolumn{2}{|c|}{ Voluntary Donors } & \multicolumn{2}{c|}{ Replacement Donors } \\
\cline { 4 - 7 } & & Tonors & Total & HBV Positive & Total & HBV Positive \\
\hline 2012 & 10489 & $167(1.60 \%)$ & $8477(80.82 \%)$ & $91(1.07 \%)$ & $2012(19.18 \%)$ & $76(3.78 \%)$ \\
\hline 2013 & 10535 & $161(1.53 \%)$ & $8950(84.95 \%)$ & $108(1.20 \%)$ & $1585(15.04 \%)$ & $53(3.34 \%)$ \\
\hline 2014 & 11053 & $141(1.27 \%)$ & $9658(87.38 \%)$ & $125(1.29 \%)$ & $1395(12.62 \%)$ & $16(1.14 \%)$ \\
\hline 2015 & 9527 & $105(1.10 \%)$ & $8422(88.40 \%)$ & $97(1.15 \%)$ & $1105(11.60 \%)$ & $08(0.72 \%)$ \\
\hline 2016 & 11002 & $166(1.61 \%)$ & $10289(93.52 \%)$ & $150(1.46 \%)$ & $713(6.48 \%)$ & $16(2.24 \%)$ \\
\hline Total & 52606 & $740(1.41 \%)$ & $45796(87.05 \%)$ & $571(1.25 \%)$ & $6810(12.94 \%)$ & $169(2.48 \%)$ \\
\hline
\end{tabular}

Seropositivity for HCV was found in total $424(0.80 \%)$ donors, out of which $334(0.73 \%)$ were voluntary donors and $90(1.32 \%)$ were replacement donors (Table 4$)$.

Table 4: HCV seropositive cases in donors

\begin{tabular}{|l|c|c|c|c|c|c|}
\hline Year & \multirow{2}{*}{$\begin{array}{c}\text { Total } \\
\text { Donors }\end{array}$} & \multirow{2}{*}{$\begin{array}{c}\text { Total HCV } \\
\text { positive } \\
\end{array}$} & & \multicolumn{2}{|c|}{ Voluntary Donors } & \multicolumn{2}{|c|}{ Replacement Donors } \\
\cline { 4 - 7 } & & Total & HCV Positive & Total & HCV Positive \\
\hline 2012 & 10489 & $84(0.80 \%)$ & $8477(80.82 \%)$ & $42(0.50 \%)$ & $2012(19.18 \%)$ & $42(2.09 \%)$ \\
\hline 2013 & 10535 & $90(0.85 \%)$ & $8950(84.95 \%)$ & $60(0.67 \%)$ & $1585(15.04 \%)$ & $30(1.89 \%)$ \\
\hline 2014 & 11053 & $54(0.49 \%)$ & $9658(87.38 \%)$ & $49(0.50 \%)$ & $1395(12.62 \%)$ & $05(0.36 \%)$ \\
\hline 2015 & 9527 & $67(0.70 \%)$ & $8422(88.40 \%)$ & $62(0.73 \%)$ & $1105(11.60 \%)$ & $05(0.45 \%)$ \\
\hline 2016 & 11002 & $129(1.17 \%)$ & $10289(93.52 \%)$ & $121(1.17 \%)$ & $713(6.48 \%)$ & $08(1.12 \%)$ \\
\hline Total & 52606 & $424(0.80 \%)$ & $45796(87.05 \%)$ & $334(0.73 \%)$ & $6810(12.94 \%)$ & $90(1.32 \%)$ \\
\hline
\end{tabular}

Seropositivity for Syphilis was found in total $44(0.08 \%)$ donors, out of which $38(0.08 \%)$ were voluntary donors and $06(0.09 \%)$ were replacement donors (Table 5). 
Table 5: Syphilis seropositive cases in donors

\begin{tabular}{|c|c|c|c|c|c|c|}
\hline \multirow[t]{2}{*}{ Year } & \multirow{2}{*}{$\begin{array}{c}\text { Total } \\
\text { Donors }\end{array}$} & \multirow{2}{*}{$\begin{array}{c}\text { Total Syphilis } \\
\text { positive } \\
\text { donors }\end{array}$} & \multicolumn{2}{|c|}{ Voluntary Donors } & \multicolumn{2}{|c|}{ Replacement Donors } \\
\hline & & & Total & $\begin{array}{l}\text { Syphilis } \\
\text { Positive }\end{array}$ & Total & $\begin{array}{l}\text { Syphilis } \\
\text { Positive }\end{array}$ \\
\hline 2012 & 10489 & 00 & $8477(80.82 \%)$ & 00 & $2012(19.18 \%)$ & 00 \\
\hline 2013 & 10535 & $01(0.009 \%)$ & $8950(84.95 \%)$ & $01(0.01 \%)$ & $1585(15.04 \%)$ & 00 \\
\hline 2014 & 11053 & $03(0.02 \%)$ & $9658(87.38 \%)$ & $02(0.02 \%)$ & $1395(12.62 \%)$ & $01(0.07 \%)$ \\
\hline 2015 & 9527 & $39(0.41 \%)$ & $8422(88.40 \%)$ & $34(0.40 \%)$ & $1105(11.60 \%)$ & $05(0.45 \%)$ \\
\hline 2016 & 11002 & $01(0.009 \%)$ & $10289(93.52 \%)$ & $01(0.01 \%)$ & $713(6.48 \%)$ & 00 \\
\hline Total & 52606 & $44(0.08 \%)$ & $45796(87.05 \%)$ & $38(0.08 \%)$ & $6810(12.94 \%)$ & $06(0.09 \%)$ \\
\hline
\end{tabular}

Screening for Malaria showed seropositivity in only $01(0.002 \%)$ donor, which was a voluntary donor $(0.002 \%)$ The overall seropositivity for all TTIs over a period of five years was found to be $1425(2.71 \%)$ in which 1081 $(2.36 \%)$ were voluntary donors and $344(5.05 \%)$ were replacement donors (Table 6).

Table 6: Overall seropositivity in TTIs (HIV, HBV, HCV, Syphilis \& Malaria)

\begin{tabular}{|l|c|c|c|c|c|c|}
\hline Year & \multirow{2}{*}{$\begin{array}{c}\text { Total } \\
\text { Donors }\end{array}$} & \multirow{2}{*}{$\begin{array}{c}\text { Seropositivity } \\
\text { in TTIs }\end{array}$} & \multicolumn{2}{|c|}{ Voluntary Donors } & \multicolumn{2}{|c|}{ Replacement Donors } \\
\cline { 4 - 7 } & & & Total & $\begin{array}{c}\text { Seropositivity } \\
\text { in TTIs }\end{array}$ & Total & $\begin{array}{c}\text { Seropositivity } \\
\text { in TTIs }\end{array}$ \\
\hline 2012 & 10489 & $327(3.11 \%)$ & $8477(80.82 \%)$ & $167(1.97 \%)$ & $2012(19.18 \%)$ & $160(7.95 \%)$ \\
\hline 2013 & 10535 & $330(3.13 \%)$ & $8950(84.95 \%)$ & $214(2.39 \%)$ & $1585(15.04 \%)$ & $116(7.32 \%)$ \\
\hline 2014 & 11053 & $221(1.20 \%)$ & $9658(87.38 \%)$ & $197(2.04 \%)$ & $1395(12.62 \%)$ & $24(1.72 \%)$ \\
\hline 2015 & 9527 & $236(2.48 \%)$ & $8422(88.40 \%)$ & $216(2.56 \%)$ & $1105(11.60 \%)$ & $20(1.81 \%)$ \\
\hline 2016 & 11002 & $311(2.82 \%)$ & $10289(93.52 \%)$ & $287(2.78 \%)$ & $713(6.48 \%)$ & $24(3.36 \%)$ \\
\hline Total & 52606 & $1425(2.71 \%)$ & $45796(87.05 \%)$ & $1081(2.36 \%)$ & $6810(12.94 \%)$ & $344(5.05 \%)$ \\
\hline
\end{tabular}

\section{Discussion}

In present study, a total of 52606 donor's were collected over the period of 5 years (From $1^{\text {st }}$ January 2012 to $31^{\text {st }}$ December 2016). Out of these 45,796 $(87.05 \%)$ were voluntary blood donations and 6,810 $(12.94 \%)$ were replacement Blood donations which correlates with studies of Tulika Chandra et $\mathrm{al}^{7}$ and Kirana Pailoor et $\mathrm{al}^{8}$ in which $93.77 \%$ \& $79.82 \%$ were voluntary donors and $6.23 \%$ and $20.21 \%$ were replacement donors respectively.

The overall prevalence rate in our study for HIV, $\mathrm{HBV}, \mathrm{HCV}$, Syphilis and Malaria was found to $0.41 \%$, $1.41 \%, 0.80 \%, 0.08 \%$, and $0.002 \%$ respectively. These findings correlate with studies of Kirana Pialoor et $\mathrm{al}^{8}$ where prevalence rate were $0.06 \%, 0.30 \%, 0.06 \%$, $0.12 \%$ and $0.01 \%$ respectively. Our finding also correlates with T. Pallavi et $\mathrm{al}^{9}$ where prevalence rate was $0.44 \%, 1.27 \%, 0.23 \%, 0.20 \%$ and 00 respectively. Among the entire TTIs, prevalence rate for HBV was found to be highest.

The overall seropositivity for all TTIs over a period of five years was found to be 1425 (2.71\%) in which $1081(2.36 \%)$ were voluntary donors and $344(5.05 \%)$ were replacement donors. This suggests TTIs are more common among Replacement donors as compared to voluntary donors which correlates with studies of Tulika Chandra et $\mathrm{al}^{7}$, Kirana Pailoor et al,${ }^{8}$ T. Pallavi et $\mathrm{al},{ }^{9}$ Hilda Fernandes et $\mathrm{al}^{3}$ and Misganaw Birhaneselassie. ${ }^{10}$ These findings can be attributed to the increase in awareness among donors due encouragement by various NGOs and Governmental organizations. The cause for increase number of TTIs among replacement donors can be due to hiding of medical history by donors due to peer pressure.

\section{Conclusion}

The low prevalence of TTIs among voluntary donors indicates that, to reduce the risk of TTIs non remunerated voluntary donor services need to be instituted. To improve blood safety extensive donor selection, use of sensitive screening and establishing strict guidelines in blood transfusion will help us to reduce burden of TTIs in our society.

Abbreviations: TTIs: Transfusion Transmitted Infections, HIV: Human Immunodeficiency Virus, HBV: Hepatitis B Virus, HCV: Hepatitis C Virus.

\section{References}

1. Transfusion Medicine Technical Manual, Directorate General of Health Services, Ministry of Health and Family Welfare, Government of India. $2^{\text {nd }}$ Edition, 2003, pg. 1.

2. Widman FK (ed) (1985) Technical manual. American Association of Blood Banks, Arlington, pp 325-344.

3. Hilda Fernandes, Prema Fancy D'souza, and Pushpa Maria D'souza. Prevalence of Transfusion Transmitted Infections in Voluntary and Replacement Donors. Indian J Heematol Blood Transfus. 2010;26(3):89-91. 
4. WHO. Screening Donated Blood for TTIs: Recommendations. Geneva: WHO; 2010. p. 6.

5. National AIDS Control Organization (NACO, India). Standards for Blood Banks \& Blood Transfusion Services. New Delhi: NACO, Ministry of Health and Family Welfare, Government of India; 2007.

6. "Disease burden in India: Estimations and casual analysis," NCMH Background Papers - Burden of Disease in India, 2005.

7. Tulika Chandra, S Nishat Fatima Rizwi and Devisha Agarwal. Decreasing prevalence of Transfusion Transmitted Infection in Indian Scenario. The Scientific World Journal. Vol. 2014 (2014).

8. Kirana Pailoor, Murali Keshava S, Prajwith Rai, Olivia D'Cunha and Lakshmi C. A Retrospective Study of Screening of Common Transfusion Transmitted Infections in Blood Bank of a Tertiary Care Centre. Journal of Blood Disorders and Transfusion. 2015.

9. T. Pallavi, CK Ganesh, K Jayashree and GV Manjunath. Seroprevalance and Trends in Transfusion Transmitted Infections Among Blood Donors in University Hospital
Blood Bank: A 5 Year Study. Indian J Hematol Blood Transfus. 2011;27(1):1-6.

10. Misganaw Birhaneselassie, MSc. Prevalence of Transfusion - Transmissible Infections in Donors to an Ethiopian Blood Bank between 2009 and 2013 and Donation Factors That Would Improve the Safety of the Blood Supply in Underdeveloped Countries. Laboratory Medicine. 47:2:134-139.

How to cite this article: Tayde A, Agrawal C, Deshmukh AT. Seroprevalence of transfusion transmitted infections in voluntary and replacement donors: A five years study. J Diagn Pathol Oncol. 2018;4(3):228-231. 